\title{
INTERCULTURALIDADE, JURISDICÃO INDÍGENA E A CONSTITUIÇÃO FEDERAL DE 1988
}

\author{
Erika Macedo Moreira \\ Ana Catarina Zema de Resende
}

\begin{abstract}
Resumo:
Desde o início da colonizacão, os povos indígenas têm resistido às sucessivas tentativas de desestruturação social e de sua capacidade de autogoverno, inclusive em matéria de justiça. Apesar da violência colonial, de séculos de políticas assimilacionistas e dos postulados monistas da sociedade dominante, eles lograram conservar seus sistemas iurídicos próprios. No entanto, em um contexto em que o Estado continua mantendo e reproduzindo a colonialidade do poder como lógica dominante da razão iurídica, a coexistência das culturas jurídicas indígenas com a estatal permanece problemática. Esse artigo pretende examinar em que medida o quadro constitucional brasileiro determina a recepção da jurisdição indígena.
\end{abstract}

Palavras-chave: Jurisdiç̃o Indígena; Interculturalidade; Pluralismo Jurídico; Novo Constitucionalismo, Constituição Federal.

\section{INTERCULTURALITY, INDIGENOUS JURISDICTION AND THE FEDERAL CONSTITUTION OF 1988}

\begin{abstract}
:
Since the beginning of colonization, indigenous peoples have resisted successive attempts aimed at social disorganization and the destruction of their capacity for self-government, including their iustice system. Despite colonial violence, centuries of assimilationist policies, and monistic postulates of the dominant society, indigenous peoples managed to preserve their own legal systems. However, in a context in which the state continues to maintain and reproduce the coloniality of power as the dominant logic of legal reason, the coexistence of indigenous legal cultures and state remains problematic. This article intends to examine to what extent the Brazilian constitutional framework determines the reception of the indigenous jurisdiction.
\end{abstract}

Kevwords: Indigenous Jurisdiction; Interculturality; Legal Pluralism; New Constitutionalism, Federal Constitution.

\section{Introdução}

A luta dos povos indígenas pelo reconhecimento e pela preservação de suas culturas jurídicas não é nova. Desde o início da colonização, eles têm resistido às sucessivas tentativas de desestruturação social e aniquilação de sua capacidade de autogoverno, inclusive em matéria de justiça. Apesar da violência colonial, de séculos de políticas assimilacionistas e dos postulados monistas da sociedade dominante, eles 
lograram conservar seus sistemas jurídicos próprios. No entanto, em um contexto em que o Estado, nas suas relações com os povos indígenas, continua mantendo e reproduzindo a colonialidade do poder como lógica dominante da razão jurídica, a coexistência das culturas jurídicas indígenas com a estatal permanece problemática. Muitos povos indígenas, ainda hoje, devem se mobilizar para obter dos Estados onde vivem o reconhecimento de seu direito à autodeterminação, particularmente quanto à aplicação de sua ordem normativa.

Nos debates sobre o "Novo Constitucionalismo" Latino-americano, o tema do reconhecimento da jurisdição indígena foi central. Desde então, muitas pesquisas foram realizadas sobre a questão do pluralismo jurídico e das jurisdições indígenas. Mesmo assim, é possível constatar que os sistemas jurídicos desses povos permanecem desconhecidos e invisibilizados aos olhos da grande maioria. Existem ainda muitas dúvidas sobre as especificidades das jurisdições indígenas e isso acaba por dificultar sua compreensão e uma abertura para o diálogo com as culturas jurídicas ocidentais. No Brasil, são raros os estudos sobre essa temática o que reforça ainda mais uma série de preconceitos e leituras discriminatórias por parte dos juízes, advogados e sociedade em geral.

Esse artigo pretende examinar em que medida o quadro constitucional brasileiro determina a recepção da jurisdição indígena, quais os desafios que esse reconhecimento coloca para o direito nacional e, finalmente, até que ponto as mudanças recentes no direito constitucional brasileiro são capazes de amparar uma pluralidade jurídica mais igualitária que atenue a lógica hegemônica e hierárquica do direito oficial. Para a análise da proteção constitucional da jurisdição indígena e de seus desafios, recorremos aos pressupostos teóricos da Interculturalidade Crítica como pensados por Catherine Walsh.

\section{Interculturalidade Crítica e Interlegalidade}

O modelo teórico da Interculturalidade Crítica desenvolvido por Catherine Walsh e as reflexões de Raquel Yrigoyen Fajardo e de Boaventura de Sousa Santos sobre o Pluralismo Jurídico nas novas constituições da América Latina oferecem parâmetros necessários para a compreensão e avaliação dos avanços e limites da proteção constitucional da jurisdição indígena no Brasil.

Desde os anos 1990, na América Latina, uma nova atenção é dada à diversidade étnico-cultural com o reconhecimento de direitos e diante da necessidade cada vez mais preeminente de lutar contra a discriminação, o racismo e a exclusão e promover relações

\footnotetext{
Rev. de Movimentos Sociais e Conflito | e-ISSN: 2525-9830| Goiânia| v. 5 | n. 1 | p. 79-94 | Jan/Jun. 2019
} 
positivas entre os diferentes grupos culturais e formar cidadãos conscientes das diferenças e capazes de trabalhar em conjunto na construção de uma sociedade justa, equitativa, igualitária e plural. A interculturalidade surge desse esforço, segundo Walsh (2016).

A compreensão do termo "interculturalidade" continua ampla e difusa sobretudo porque se tornou uma palavra em voga, usada em uma variedade de contextos para atender a interesses sociopolíticos diversos, às vezes, até opostos. $\mathrm{O}$ uso e o sentido contemporâneo e conjectural da interculturalidade pode ser explicado a partir de três perspectivas: a relacional, a funcional e a crítica (Walsh, 2016). A primeira perspectiva, a relacional, remete à ideia mais básica e geral de contato e troca entre culturas. Essa perspectiva, no entanto, tende a obscurecer e minimizar a conflitualidade e as relações de poder, dominação e a colonialidade em curso. A segunda perspectiva da interculturalidade é a funcional. De acordo com essa perspectiva, a interculturalidade está enraizada no reconhecimento da diversidade e da diferença cultural com objetivos para sua inclusão na estrutura social estabelecida. Essa perspectiva "não toca as causas da assimetria e da desigualdade social e da cultura, nem questiona as regras do jogo e, portanto, é perfeitamente compatível com a lógica do modelo neoliberal existente" (WALSH, 2016, online).

A terceira perspectiva - a que seguimos neste artigo - é a da Interculturalidade Crítica. O que interessa nessa perspectiva não é o problema da diversidade ou da diferença em si, mas o problema da estrutura colonial-racial. Ou seja, o reconhecimento de que a diferença é construída em uma estrutura colonial e matriz de poder racializado e hierárquico, onde os brancos estão acima e os povos indígenas e afrodescendentes são inferioriorizados. Nessa perspectiva, a interculturalidade é entendida como uma ferramenta e como um projeto político que é construído a partir das pessoas marginalizadas. "Aponta e requer a transformação de estruturas, instituições e relações sociais, e a construção de condições de ser, pensar, conhecer, aprender, sentir e viver diferente" (WALSH, 2016, online).

Para Walsh (2009), o paradigma da interculturalidade deve ser entendido a partir da práxis política dos grupos sociais que buscam superar a estrutura de dominação imposta aos povos indígenas desde a colonização. Está relacionado, portanto, à capacidade de construção dos novos sentidos, olhares e práticas diante do "outro", do diferente. Nesse sentido, os conteúdos da diversidade cultural remetem ao reconhecimento, estímulo e valorização das formas próprias de organização social, cultural, econômica e política que os povos indígenas e as populações tradicionais 
produzem nos seus modos de vida, e como o Estado organiza os espaços, mecanismos e formas de interação social que, no espaço público, legitima as novas formas de tratamento diferenciado do "outro".

O pluralismo jurídico aponta para a necessidade de mudanças nas estruturas jurídicas do Estado. Não se trata de um fenômeno novo, mas de uma realidade histórica bastante estudada e conhecida dos historiadores do direito. A novidade está em seu reconhecimento por parte das entidades internacionais e dos Estados com relação à aceitação da coexistência das práticas e sistemas ancestrais para o exercício da justiça nas sociedades indígenas e de raiz africana (WALSH, 2010). O pluralismo jurídico sinaliza para a necessidade de uma ação transversal, coordenada e intencional pelo Estado, no sentido de reconhecer, valorizar e adotar medidas de fortalecimento da autodeterminação dos povos, também na busca pela resolução de seus conflitos.

Boaventura de Sousa Santos (1998) identifica três manifestações de pluralismo jurídico no processo histórico brasileiro: 1) no ângulo colonial, quando aplicado o direito oficial português na colônia; 2) o direito dos povos indígenas; 3) em decorrência da exclusão social. No entanto, para o autor, com o avanço da globalização, a consolidação das instâncias e mecanismos de negociação supranacionais, há uma pluralidade de diversos sistemas normativos, no mesmo espaço e tempo, que dá origem a um conjunto de influências mútuas que se estabelecem como estratégia de sobrevivência de cada uma das esferas das constelações jurídicas, dando origem ao conceito de hibridações jurídicas (SOUSA SANTOS, 2003).

Das hibridizações jurídicas surge o conceito de interlegalidade, isto é, o cruzamento de diferentes direitos na resolução dos problemas:

Consoante as situações e os contextos, os cidadãos e os grupos sociais organizam as suas experiências segundo o direito oficial estatal, o direito consuetudinário, o direito comunitário, local, ou o direito global, e, na maioria dos casos, segundo complexas combinações entre estas ordens jurídicas (SOUSA SANTOS, 2003, p. 49-50).

A interlegalidade refere-se à desconstrução do sistema jurídico centrado no indivíduo de matriz colonial e busca acabar com a hierarquia dos sistemas normativos, reconhecendo que cada um possui um sentido e uma prática própria, embora haja articulação e complementariedade entre eles. Portanto, instituí uma nova dinâmica, diluindo fronteiras entre o que seja direito individual e coletivo, pois considera a normatividade histórica, a autonomia e diversidade das formas de vida e pluraliza o 
sistema nacional.

A Interculturalidade Crítica e o conceito de interlegalidade como parâmetros teóricos para pensar os desafios da proteção constitucional da jurisdição indígena no Brasil serão tomados aqui como um projeto político, social, ético e epistêmico de caráter e orientação descolonizador que implica a transformação e a construção de condições de ser, pensar, sentir, conhecer e viver distintas. Seguindo essa proposta teórica, não se trata apenas de "afirmar a necessidade de uma mudança das relações, mas também das estruturas, condições e dispositivos de poder que mantêm a desigualdade, inferiorização, racialização, discriminação, incluindo as estruturas jurídicas" (WALSH, 2010, p. 6).

Ainda que a Constituição Federal de 1988 do Brasil esteja situada por Raquel Yrigoyen Fajardo (2010b) no primeiro ciclo das reformas constitucionais pluralistas, entendemos que, por ser instrumento formal de materialização de direitos, seu marco normativo dialoga com os conteúdos expressos nos debates internacionais atuais que possuem plena efetividade no sistema jurídico nacional, devendo ser interpretados enquanto conceitos dinâmicos que reconhecem o valor da diversidade cultural e da busca por emancipação social.

\section{A Constituição Federal de 1988 e o novo constitucionalismo latino-americano}

A Constituição Federal de 1988 é comemorada por instituir uma nova relação entre Estado e povos indígenas, uma vez que reconhece aos índios o direito de ser índio, e manter-se como índio, rompendo com toda a legislação indigenista anterior de caráter eminentemente integracionista, e atribuindo à União o dever de proteger e fazer respeitar todos os bens indígenas.

Assim, o artigo 231 ao reconhecer aos índios sua organização social, costumes, línguas, crenças e tradições, e os direitos originários sobre as terras que tradicionalmente ocupam, competindo à União demarcá-las, proteger e fazer respeitar todos os seus bens, inaugura, no constitucionalismo brasileiro, sua concepção pluralista e comunitarista, pautada no reconhecimento da diversidade cultural e social como fonte de fortalecimento do Estado e da democracia. Desta forma, na busca pela garantia dos direitos étnicos e efetivação das políticas interculturais, diante do histórico conflito com o Estado, os povos indígenas acabam por recolocar em debate questões estruturantes, como democracia, governo e direito (SOUSA SANTOS, 2010).

Neste contexto, as reformas constitucionais do Brasil (1988), Colômbia (1991), Peru (1993), Equador (1998 e 2008), Venezuela (1999) e Bolívia (2009) são festejadas 
por colocar ao Estado a necessidade de criar conceitos e instituições capazes de materializar políticas públicas de garantia da diversidade cultural, especialmente para os povos indígenas. No campo do acesso à justiça, inovam com questões relacionadas a administração da justiça, como autogoverno e jurisdição própria, onde as autoridades indígenas passam a ter seus direitos expressamente reconhecidos.

As novas Constituições latino-americanas inovam ao trazer para o sistema jurídico formal o reconhecimento de outra instância de resolução de conflitos que se pauta na ancestralidade e na competência de suas autoridades locais, com base nos princípios, valores, práticas culturais, normas e procedimentos jurídicos próprios de seus povos. $\mathrm{Na}$ medida em que trazem mecanismos, princípios e objetivos que permitem o avanço e a emancipação do povo, as novas constituições radicalizam o constitucionalismo, já que a constituição é o mandato direto do poder constituinte e, por consequência, fundamento último da razão de ser do poder constituído (VICIANO PASTOR, 2012).

Para o caso brasileiro, embora não tenhamos a incorporação expressa da jurisdição especial indígena ou do pluralismo jurídico, a participação indígena marcou o processo constituinte (LACERDA, 2008). Aliado à presença de apoiadores da causa, essa participação constituiu fator determinante para o reconhecimento dos direitos indígenas, estando as normas constitucionais de 1988 dotadas, portanto, da legitimidade do poder constituinte.

O constitucionalismo contemporâneo ou "novo constitucionalismo" - ou mesmo neoconstitucionalismo -, inaugurado especialmente pelas constituições latino-americanas, caracteriza-se não só pelo controle de constitucionalidade e o princípio da supremacia constitucional, mas também pelas garantias dos direitos fundamentais, em especial, das minorias étnicas, em sua dimensão real e concreta, passando pelo reconhecimento da diversidade política, cultural e social.

No campo da jurisdição indígena, nos países andinos, seu reconhecimento ficou atrelado aos mecanismos alternativos de resolução de conflitos:

En algunos casos, tal promoción se dio mediante donaciones y, en otros, mediante préstamos a los estados, préstamos condicionados a cierta visión de las reformas de la justicia. Estas reformas permitieron una apertura ideológica, y en algunos casos financiamiento, para impulsar el reconocimiento de la justicia indígena, pero concebida fundamentalmente como una forma alternativa de resolución de conflictos locales para las comunidades indígenas pobres, y en tanto sólo resolvieran conflictos menores. No estaba dentro de este esquema que los pueblos indígenas pudieran tener poder jurisdiccional en sus territorios para resolver, por ejemplo, conflictos con 
corporaciones transnacionales, o extraños. Ni tampoco cabía el reconocimiento de funciones jurisdiccionales que dieran a los colectivos un poder absoluto sobre los individuos, y que impidiera a éstos desarrollar procesos de individuación para poder moverse en el mercado, como en el caso de las mujeres. Esta influencia se nota, por ejemplo, en la fórmula de constituciones como la Bolivia de 1994, en el marco del neoliberalismo, que reconocen la justicia indígena en tanto "mecanismos alternativos de resolución de conflictos", o la de Ecuador, para "conflictos internos" (YRIGOYEN FALARDO, 2010a, mimeo, s/n) (grifos nossos).

No Brasil, ainda não houve a adoção de medidas regulamentadoras do acesso à justiça para comunidades indígenas. Apenas um grupo de trabalho constituído no âmbito da XIV Conferência Judicial Iberoamericana, ocorrido em 2008. Esse grupo de trabalho elaborou um documento intitulado "Regras de Brasília sobre Acesso à Justiça das Pessoas em condição de Vulnerabilidade". Entre as 100 Regras de Brasília para o acesso à justiça das pessoas em condição de vulnerabilidade, as de número 48 e 49 apontam os indígenas como um dos grupos de pessoas em condições de vulnerabilidade, destacando a importância de estimular as formas próprias de justiça, para resolução de conflitos internos surgidos nas comunidades indígenas, bem como a necessidade de harmonizar o sistema de administração de justiça estatal e indígena, baseado nos princípios de respeito mútuo e de convivência com as normas internacionais de direitos humanos (CONFERÊNCIA JUDICIAL IBERO-AMERICANA, 2008).

\section{Desafios para o reconhecimento da jurisdição indígena no Brasil}

A Constituição Federal de 1988 inaugurou, no Brasil, o constitucionalismo de perspectiva pluralista e comunitarista, ao assegurar medidas protetivas dos direitos individuais e também das coletividades, com a recepção de valores culturais diversos e dinâmicos presentes na sociedade, que exigem uma nova forma de interpretar a Constituição. O conjunto dos dispositivos constitucionais que a Constituição Federal de 1988 inaugura está relacionado a uma nova dimensão do Estado e do direito, onde a garantia constitucional de reconhecimento da existência de povos indígenas com organização social própria faz com que a legitimidade das ações estatais passe pela aceitação e criação de mecanismos de reconhecimento e fortalecimento da diversidade cultural, expressos nos modos de vida, cultura, costumes e sistemas normativos plurais. Em contraposição à noção de sujeito individual de direitos, temos o reconhecimento dos direitos coletivos, em oposição à ideia da propriedade individual da terra, temos o 
usufruto do território, contra o monismo estatal, o reconhecimento dos usos, costumes e tradições (o que abre caminho para pensarmos no pluralismo jurídico e na jurisdição indígena).

Estes desafios podem ser classificados em três dimensões da mudança de paradigma: da tutela-proteção; da diversidade de modos de vida; da identidade e autodeterminação (MOREIRA, 2014).

O primeiro desafio imposto pela Constituição Federal de 1988 foi no sentido de superar, ao menos do ponto de vista normativo, séculos de política integracionista; e, instituir, em oposição, o paradigma da diferença e da interação. Até 1988, a incorporação dos "silvícolas" havia sido o objetivo mais importante da política indígena, sendo tema das Constituições, desde 1934 e do Estatuto do Índio de 1973. Atrelado ao paradigma da incapacidade, a política integracionista considerava que as comunidades indígenas se encontravam em nível inicial do processo de evolução, e por isso era necessário a incorporação daquela cultura, na sociedade nacional, mais evoluída, progressista e moderna.

Com a Constituição Federal de 1988, o sentido da tutela transfigura-se da tutelaincapacidade para a tutela-proteção, uma vez que a diversidade das manifestações sociais e culturais passa a ser visto como fonte de riqueza cultural. Nesse sentido, vale destacar a importância das pesquisas empíricas da Antropologia que derrubaram o paradigma da inferioridade e comprovaram que os "chamados povos primitivos dispunham de culturas completas e funcionais que em nada ficam atrás das chamadas 'culturas dos civilizados', no que diz respeito ao desenvolvimento e perspicácia de seu pensamento" (KAYSER, 2010, p. 210).

O paradigma da tutela-proteção está relacionado, portanto, a uma visão do direito que reconhece e valoriza a diversidade social, cultural e jurídica. $\mathrm{O}$ que pressupõe superar a redução do direito à lei, e mais ainda, à lei de matriz ocidental, rompendo assim com o pensamento jurídico tradicional que optou por consolidar um conceito de pluralismo jurídico associado ao paradigma da inferioridade, reduzindo o direito consuetudinário (ou direito "primitivo") dos povos autóctones, ao direito imperial/colonial. Aqueles, sempre colocados num plano de submissão e inferioridade, em relação ao último.

Tal mudança (ao menos do ponto de vista formal), na forma de se relacionar com os indígenas implica o desenvolvimento de ações e políticas públicas que almejem superar o racismo institucional expresso até mesmo nos órgãos responsáveis pela proteção dos povos indígenas e o modelo autoritário de desenvolvimento que desconsidera as opções dos povos em relação a seus modos de vida. 
O segundo desafio da mudança de paradigma da Constituição Federal de 1988 está relacionado à importância e ao reconhecimento dos usos, costumes e tradições, enquanto instrumentos de tradução de "outras" lógicas sociais, espaciais e territoriais dos povos, a partir de "outro" conjunto de significados e regras sociojurídicas, traduzidos pelo sistema jurídico tradicional enquanto direitos consuetudinários. Assim, pressupõe a superação tradicional do conceito de pluralismo jurídico no âmbito da sistemática constitucional, para reconhecimento do pluralismo como fonte de desenvolvimento de políticas coordenadas de coexistência de sistemas jurídicos no mesmo espaço e tempo, fortalecendo o Estado com o reconhecimento dessa diversidade viva de formas de resolver conflitos.

O terceiro desafio da Constituição Federal de 1988 está relacionado à identidade e à autodeterminação, um direito coletivo expresso nos modos próprios de vida e opções de modelo de desenvolvimento dos povos indígenas. Assim, abarcam dupla dimensão: tanta na perspectiva do direito difuso de todos à existência e manutenção da cultura dos diversos povos, com respeito e integridade; como também das pessoas de cada povo se reconhecer enquanto pertencentes daquele povo e não de outro. Relacionam-se, portanto, a autodeterminação e ao pertencimento, vinculados aos modos de vida, cultura, língua e garantia de manejo dos seus territórios, a partir de seus usos, costumes e tradições. Desta forma, os conteúdos da diversidade cultural estão relacionados ao tratamento políticojurídico dos "novos direitos", materializados num conjunto normativo, que nos remetem a identidade étnica e a autodeterminação.

Sentir-se parte do grupo, se identificar com a comunidade na qual se vive é uma expressão do que conhecemos por identidade. $O$ processo de construção desse sentimento de pertencimento leva em consideração um rol de fatores como os costumes e tradições desses grupos. A preservação desse sentimento de pertença que um indivíduo tem com um grupo é uma das garantias do direito à identidade étnica, que permite que o indivíduo que se sinta pertencente a um grupo social possa se afirmar como tal, preservando a sua cultura, seus valores, sua visão de mundo e coesão social. É considerado um direito fundamental, já que é uma garantia que, mesmo não estando expressamente na Constituição Federal, depreende dos princípios por ela adotados, como, por exemplo, o princípio da dignidade da pessoa humana, da liberdade de consciência e de crença.

Mesmo não estando expresso no texto constitucional - direito à autodeterminação - podemos perceber referências à proteção desse direito em diversos dispositivos. Já no preâmbulo, o constituinte estabelece que uma das finalidades da República Federativa do Brasil é a criação de uma "sociedade fraterna, pluralista e sem preconceitos" (Brasil, 
1988). Embora haja outras referências à garantia do direito à identidade, como nos artigos 215 e 216 do diploma constitucional, que versa da ordem social, mais especificamente sobre a cultura, a liberdade de crença e de religião, etc. "Os direitos culturais não são apenas os ligados ao respeito ao exercício de suas tradições, festas, alimentação, mais do que isso é o Direito a que as informações sobre o povo não sejam recobertas por um manto de preconceito, desprezo e mentiras" (SOUZA FILHO, 2012, p. 158).

Portanto, para Constituição Federal de 1988, os povos indígenas deixam de ser considerados culturas em extinção, fadadas à "incorporação à comunhão nacional" e passam a ter a diversidade cultural reconhecida e protegida pelo Estado, que determinou ao próprio Estado o dever de garantir sua reprodução e aos índios o direito à sua organização social, usos, costumes e tradições - e, portanto, as formas próprias de construção e efetivação dos seus sistemas jurídicos.

Além disso, entre os direitos coletivos reconhecidos, o direito ao território é o fundamento para garantir a reprodução de seus modos de vida e está relacionado ao processo demarcatório das terras. A Constituição Federal de 1988 reconheceu os direitos originários dos índios sobre seus territórios, a partir de quatro elementos fundamentais: terras habitadas; utilizadas; imprescindíveis à preservação da natureza; e, necessárias ao bem-estar e reprodução física e cultural do grupo. O reconhecimento dos direitos originários impôs limites ao poder discricionário do Estado, que passa a ter de respeitar usos, costumes e tradições e fica impedido de "'liberar' terras para exploração ou uso público, como estradas ou projetos desenvolvimentistas" (SOUZA FILHO, 2002, p. 54).

Interessante observar que toda esta normatividade é reflexo, no todo ou em parte, das conquistas legais, com suas contradições, produzidas no âmbito internacional. Diante dos conflitos entre grupos sociais minoritários e Estado, uma série de normatividades, que reconhecem o conteúdo da diversidade e da cultura, foi sendo produzida, delineando os paradigmas da interculturalidade e da descolonialidade. Entre elas, destaca-se a Convenção n. ${ }^{\circ} 169$ da OIT, aprovada em 1989, sobre Povos Indígenas e Tribais em Países Independentes, e, que foi ratificada pelo governo brasileiro através do Decreto $\mathrm{n} .^{\circ} 5.051$, de 19 de abril de 2004. A Convenção n 169 mantêm relação com os debates produzidos na ONU, pelo Grupo de Trabalho sobre Populações Indígenas da Subcomissão sobre Minorias e Discriminação da Comissão de Direitos Humanos da ONU, instituído em 1982 e que vinha criticando a ausência de instrumentos internacionais garantidores dos direitos dos povos indígenas. Surge das críticas à Convenção $\mathrm{n}^{\circ} 107$ e sua perspectiva eurocêntrica, como se os índios fossem integrar-se à comunhão nacional e deixar de reivindicar um lugar diferenciado enquanto grupo sociocultural. Por isso, a Convenção $\mathrm{n}^{\circ}$ 
169 inovou e constitui uma mudança de paradigma ao valorizar a manutenção e o desenvolvimento dos povos indígenas como coletividades distintas (BARBOSA, 2001), que possuem instituições, formas de vida, modelo de desenvolvimento econômico, social e cultural, na busca pela manutenção e fortalecimento de sua identidade, línguas e religiões.

Em 2007, após 22 anos de discussão, debates ideológicos, negociações diplomáticas e geopolíticas, durante a $107^{\mathrm{a}}$ Assembleia Geral da ONU, foi aprovada a Declaração das Nações Unidas sobre os Direitos dos Povos Indígenas (STAVENHAGEN, 2010). Entre outros aspectos aborda a reafirmação da democracia dos direitos legais; a preocupação com as injustiças históricas; o reconhecimento de promover os direitos intrínsecos dos povos indígenas; a consolidação da organização política, social, econômica e cultural; o direito aos territórios e suas terras tradicionais; o reconhecimento às culturas e às práticas tradicionais indígenas; o direito à educação escolar específica e intercultural; o respeito aos direitos humanos e à autodeterminação. $\mathrm{O}$ direito à autodeterminação implica a livre determinação de sua condição política e o direito de determinar e elaborar suas prioridades e estratégias para o exercício do seu direito ao desenvolvimento econômico, social e cultural, especialmente em relação a suas terras, territórios e recursos. Além do direito que os povos e as pessoas têm de pertencerem a uma comunidade ou nação indígena, em conformidade com as tradições e costumes da comunidade ou nação em questão, não sendo permitida qualquer discriminação resultante do exercício desse direito. A Declaração representa um plano de ação para as políticas de fortalecimento da diversidade cultural dos Estados, governos, sociedade civil e povos indígenas que possuem o compromisso de garantir respeitar e proteger os direitos indígenas e obriga, enquanto instrumento universal de direitos humanos, "moral e politicamente a todos os Estados membros da ONU à plena aplicação de seu conteúdo" (STAVENHAGEN, 2010, p. 378).

\section{Considerações finais}

O desenvolvimento recente da doutrina sobre os direitos dos povos indígenas e seu reconhecimento constitucional coloca para o Estado brasileiro o desafio de rever sua postura hegemônica e hierárquica tradicional com relação à jurisdição indígena. A negação da cultura jurídica indígena por parte do Estado tem acarretado, ao longo da história, uma série de injustiças coletivas e individuais. Não reconhecer o direito dos povos indígenas de gerir sua sociedade a partir dos princípios ancorados em sua cultura e 
cosmovisão é impedir que as pessoas vivam plenamente sua cultura. De acordo com Boaventura de Sousa Santos, a luta dos povos indígenas pela preservação de suas culturas jurídicas está ligada a uma luta mais ampla contra as sucessivas tentativas de assimilação e a recusa por parte do Estado em reconhecer a jurisdição indígena tem sido "um elemento central de dominação etnocrática através dos séculos" (apud CHICOINEWILSON, 2015, p. 4).

As relações de dominação resultantes da experiência colonial europeia moderna se fundaram na ideia da inferioridade racial ou étnico-cultural dos povos colonizados. Além da colonização político-administrativa, o colonialismo implicou uma colonização epistêmica para justificar e garantir essa ideia da inferioridade racial. Problematizar o colonialismo e as relações de poder coloniais que se mantêm nos dias de hoje sob a forma de colonialidade do poder, do ser e do saber, significa questionar a hegemonia dos conhecimentos postos como universais, entre eles, o monismo e o positivismo jurídico (ZEMA, 2014).

A concepção de direito proposta pela ideologia do sistema mundo moderno/colonial e fundada sobre o monismo e positivismo não se sustenta mais hoje como hipótese para pensar o direito nas sociedades multiculturais. As reivindicações dos movimentos indígenas nas Américas mostraram que, na verdade, o monismo e o positivismo jurídico são obstáculos para um conhecimento mais profundo do direito. De fato, pensar o direito considerando apenas o "monismo jurídico" a partir da perspectiva da moderna racionalidade eurocêntrica representa um empobrecimento muito limitador com relação às outras possibilidades de conhecer e interpretar o mundo. Nesse sentido, descolonizar o direito significa reconhecer como legítimas outras culturas jurídicas. A negação da existência ou da validade das culturas jurídicas não estatais impede um diálogo que permitiria o enriquecimento mútuo das culturas. Para Sousa Santos (2002), perder essa oportunidade de diálogo equivale a um desperdício das experiências e saberes que poderiam enriquecer a reflexão sobre soluções para os problemas e dificuldades que o direito estatal encontra. $\mathrm{O}$ monismo jurídico é uma dessas teorias dominantes que provoca a perda de experiências e de práticas jurídicas e que legitima um enorme "juricídio" (SOUSA SANTOS apud CHICOINE-WILSON, 2015, p. 6).

Os países da América Latina que já reconheceram em suas Constituições os direitos indígenas e o pluralismo legal ainda têm um caminho a percorrer para a construção de um Estado pluricultural mais igualitário e que respeite as diferenças. A tarefa normativa não terminou. Falta uma maior apropriação dessas reformas por parte da sociedade civil em geral e por parte dos povos indígenas. Dada a situação de 
marginalização histórica dos povos indígenas, esforços deverão ser realizados para que eles não sejam mais apenas receptores das normas impostas pelo Estado, mas que possam usufruir dos direitos garantidos constitucionalmente e participar da elaboração normativa para o estabelecimento de mecanismos consensuais, plurais e democráticos de coordenação entre os sistemas jurídicos (YRIGOYEN FAJARDO, 2000).

No Brasil, a proteção constitucional da jurisdição indígena não é suficiente para torna-la efetiva. Houve, como procuramos mostrar nesse artigo, um reconhecimento de fato do pluralismo jurídico pelo Estado, no entanto, mesmo após 30 anos da promulgação da Constituição Federal brasileira, ainda não houve um processo que permitisse uma coordenação coerente dos dois sistemas jurídicos. Uma das principais armadilhas é a falta de regras que definam os métodos de articulação entre o judiciário e as jurisdições indígenas, o que representa grandes desafios institucionais. Para que isso aconteça, é necessário aplicar concretamente as normas constitucionais, supranacionais (Convenção $\mathrm{n}^{\circ} 169$ da OIT e convenções internacionais de direitos humanos) e desenvolver a jurisprudência.

No contexto do constitucionalismo plural, realizar a interpretação constitucional de temas relacionados aos conflitos entre indígenas, Estado e indivíduos, pressupõe a prática do diálogo intercultural. Implica reconhecer uma pluralidade de direitos vivos, em culturas locais e em coexistência com o direito oficial no interior de um dado território. Não se trata de uma nova versão do relativismo cultural, nem como um antiocidentalismo. A questão está em enriquecer a perspectiva do universalismo a partir das dinâmicas culturais diferentes. Segundo Tubino, "a interpretação no contexto intercultural é um processo muito complexo porque interpretar não é decifrar significados objetivos, mas ressignificar-los a partir dos nossos". Nesse processo e por ação do diálogo, nossa pré-compreensão "também muda e com ela nossas possibilidades de descobrir, outorgar e construir novos sentidos" (2009, p. 162).

Pensar uma nova forma de interpretação constitucional dos direitos indígenas, na esteira da Interculturalidade crítica, é levar em conta a estrutura assimétrica de poder, entre as distintas culturas, e o impacto dos fatores econômicos, sociais, políticos e militares produzidos na relação desigual entre os povos indígenas, o Estado e proprietários privados. É necessária uma estrutura de justiça que permita a superação desta assimetria como condição para a realização do exercício hermenêutico que se desenvolve a partir da linguagem na busca pelo entendimento e efetivação dos direitos fundamentais previstos na Constituição Cidadã. 
Fica colocado o desafio de pensar estratégias de superação da prática de racismo institucional e a construção de modelos de justiça que realmente se proponham a superar todas as barreiras colocadas pela forma tradicional de se conceber o direito, em especial dos povos indígenas (como o monismo, o dogmatismo, o formalismo e a descontextualização) e caminhar para o estabelecimento de diálogos interdisciplinares que permitam a diluição das fronteiras acadêmicas e o exercício da interpretação intercultural dos direitos dos povos indígenas. É preciso resgatar a dimensão comunitarista, vitoriosa nos debates da Assembleia Nacional Constituinte, e estabelecer outros parâmetros para a construção da decisão, especialmente quando os conflitos jurídicos estão relacionados à garantia dos direitos coletivos, transindividuais e plurais.

Avançar no caminho do reconhecimento, da implementação do pluralismo jurídico e da proteção da jurisdição indígena permitiria revisitar a maioria de nossas noções e conceitos que perpetuam a colonialidade, sobretudo em um país como o Brasil de forte tradição do monismo e da juridicidade estatal. Permitiria, de acordo com a interpretação da interculturalidade crítica, enriquecer nossa tradição jurídica "de abajo hacia arriba" com princípios do direito ancestral dos povos indígenas e com suas distintas maneiras de conceber e exercer esse direito (WALSH, 2010, p. 18). Mas, sobretudo, nos ajudaria a assumir e enfrentar o racismo e a desigualdade para, finalmente, construir um Estado e uma sociedade radicalmente diferentes que não meçam esforços para melhorar o acesso à justiça para os povos indígenas, respeitando assim a realidade intercultural do nosso país.

\section{Referências}

BRASIL, 1988. Constituição da República Federativa do Brasil de 1988. Disponível em: <http://www.planalto.gov.br/ccivil_03/constituicao/constituicaocompilado.htm>. Acesso em: 24 de janeiro de 2019.

CHICOINE-WILSON, Charlotte. La reconnaissance de l'autonomie iudiciaire autochtone: regard sur l'expérience colombienne. Ottawa: Thèse soumise à la Faculté des Études Supérieures et Postdoctorales, Université d'Ottawa, 2015.

CONFERÊNCIA JUDICIAL IBERO-AMERICANA. Regras de Brasília sobre acesso à iustica das pessoas em condicão de vulnerabilidade, Brasília: 2008. Disponível em: https://www.anadep.org.br/wtksite/100-Regras-de-Brasilia-versao-reduzida.pdf. Acesso em: 23 de janeiro de 2019.

KAYSER. Hartmurt-Emmanuel. Os direitos dos povos indígenas. Desenvolvimento histórico e estágio atual. Porto Alegre: Safe, 2010.

LACERDA, Rosane. Diferenca não é incapacidade: gênese e trajetória histórica da concepção da incapacidade indígena e sua insustentabilidade nos marcos do 
protagonismo dos povos indígenas e do texto constitucional de 1988. Dissertação (mestrado). Brasília: UnB, 2007.

MOREIRA, Erika Macedo. ONHEMOIRÕ. O judiciário frente aos direitos indígenas. Tese (doutorado). Brasília: Programa de Pós-Graduação em Direito da UnB, 2014.

SOUSA SANTOS, Boaventura de. O discurso e o poder. Ensaio sobre a sociologia da retórica jurídica. Porto Alegre: Sergio António Fabris Editor, 1998.

. Towards a New Legal Common Sense. Law, Globalization and Emancipation , 2e éd., Londres, Butterworths - Lexis Nexis, 2002.

. O Estado heterogêneo e o pluralismo iurídico. In: Boaventura de Sousa Santos e outros. Conflito e Transformacão Social. Uma Paisagem das Justiças em Moçambique; Porto: Afrontamento, 2003. Vol. I., Cap. I, pp. 47-128.

. Do pós-moderno ao pós-colonial. E para além de um e outro, Conferência de Abertura do VIII Congresso Luso-Afro-Brasileiro de Ciências Sociais, Coimbra, setembro de 2004. Disponível em: <http://www.ces.uc.pt/misc/Do_pos-moderno_ao_poscolonial.pdf $>$. Acesso em: 20 dez. 2010.

SOUZA FILHO, Carlos Frederico Marés. A função social da terra. Curitiba: Juruá, 2002.

O Renascer dos Povos Indígenas para o Direito. Curitiba: Juruá, 2012

STAVENHAGEN, Rodolfo. Como hacer que la declaracion sea efectiv. In: CHARTERS, Claire: STAVENHAGEN. Rodolfo. El desafío de la Declaracíon de la ONU sobre Pueblos Indígenas. Copenhague: IWGA, 2010.

TUBINO, Fidel. Aportes de la hermenêutica diatópica al diálogo intercultural sobre los derechos humanos. In: TUBINO, Fidel; MONTEAGUDO, Cecilia (orgs.). Hermenêutica en diálogo. Ensavos sobre alteridad, lenguaje e interculturalidad. Lima/ Peru: Fondo Editorial, 2009.

VICIANO PASTOR. Roberto: DALMAU. Rubén Martínez (Org.). Cambio político y processo constituyente em Venezuela (1998-2000). Valencia: tirant lo blanch, 2001.

VICIANO PASTOR, Roberto; DALMAU, Rubén Martínez. Fundamento teórico del nuevo constitucionalismo latinoamericano, in. VICIANO PASTOR, Roberto (Org.). Estudios sobre el nuevo Constitucionalismo Latinoamericano. Valencia: tirant lo blanch, 2012.

WALSH, Catherine, Interculturalidad, estado, sociedade: luchas (de)coloniales de nuestra época. Quito - Equador: Universidad Andina Simón Bolívar/Ediciones AbyaAyala, 2009.

. Interculturalidad crítica y pluralismo iurídico. Ponencia presentada en el Seminário Pluralismo Jurídico, Procuradora del Estado/Ministerio de Justicia, Brasilia, 13-14 de abril 2010. Disponível em:

Erro! A referência de hiperlink não é válida.

- Vers une compréhension de l'interculturalité - une approche par la pédagogie décoloniale, 2016. Disponível em: $<$ https://iresmo.iimdo.com/2016/11/02/vers-unecompréhension-de-l-interculturalité-une-approche-par-la-pédagogie-décoloniale/>. Acesso em: 23 de janeiro de 2019.

YRIGOYEN FAJARDO, Raquel. Reconocimiento constitucional del derecho indígena y

Rev. de Movimentos Sociais e Conflito | e-ISSN: 2525-9830| Goiânia| v. 5 | n. 1 | p. 79-94 | Jan/Jun. 2019 
la iurisdicción especial en los países Andinos (Colombia, Perú, Bolivia, Ecuador). Revista Pena y Estado, n. 4, Buenos Aires, INECIP y Editorial el Puerto, 2000.

. Pluralismo iurídico, derecho indígena y jurisdicción especial en los países andinos. El otro derecho, n.30, jun. 2004.

. Aos 20 anos do Convênio 169 da OIT: balanço e desafio da implementacão dos direitos dos povos indígenas na América Latina. In: YRIGOYEN FAJARDO, Raquel. Como se há regulado el pluralismo iurídico en la historia latinoamericana? Curso Pre-congreso Internacional Red Latinoamericana de Antropologia Jurídica. Peru, 2010 a, mimeo.

. El pluralismo iurídico en la historia constitucional latinoamericana: de la suieción a la descolonización. In: Curso de Aperfeicoamento Pluralismo Jurídico e Multiculturalismo. Brasília: Escola Superior do Ministério Público, $2010 \mathrm{~b}$. IIDS, 2010c.

. Pueblos Indígenas. Constituciones y reformas políticas en América Latina. Lima:

ZEMA DE RESENDE, Ana Catarina. Direitos e autonomia indígena no Brasil (19602010): uma análise histórica à luz da teoria do sistema-mundo e do pensamento decolonial. Tese (doutorado). Brasília: Departamento de História. Instituto de Ciências Humanas, Universidade de Brasília, 2014. 